\title{
The Next Stage of the Reformulation Project
}

\author{
James C. Hathaway
}

Contributors to the Reformulation Project have expressed support and outlined concerns, both of which we are now seeking to develop and address. Four main areas of concern have arisen regarding our initiative to place a proposal for the fundamental restructuring of refugee law on the table at the present time:

1. There is not a consensus that the magnitude of the present crisis in the refugee protection system warrants its wholesale replacement by a new regime. Many participants believe that there is a real chance that significant protection value might be "extracted" from the creative tailoring of extant mechanisms of protection;

2. There is concern that the lack of concrete experience in the implementation of several key components of the proposed protection regime would militate against governmental interest in a reform of the kind suggested. In particular, the viability of enhanced international management of the system, the ability to humanely ensure that "temporary" protection is, at least in most cases, genuinely of finite duration, and the willingness of host governments to subscribe to an empowering model of temporary protection, were all viewed as untested hypotheses. Most of the contributors believe that, while each of these mechanisms might well prove of value, their wholesale adoption by governments was highly unlikely without clear evidence of their practicality and political acceptability;

3. Related to the second concern, it was the view of a number of con-

Professor James C. Hathaway, Director, Refugee Law Research Unit, Centre for Refugee Studies, teaches law at the Osgoode Hall Law School, York University. tributors that there was a risk of selective, protection-reducing reform if the proposal as presently conceived were formally advanced in international lawmaking circles. States might, for example, embrace a universalized commitment to temporary protection without accepting the proposed quid pro quo of burden and responsibility sharing. While others insisted that the posited "packaging" of a balanced set of reforms would, if anything, stymie the momentum of the largely state-centered reforms to refugee protection presently being implemented, most contributors felt that states should not be encouraged to feel at liberty to abandon presently accepted protection mechanisms; and

4. Fourthly, scepticism was expressed that there is a sufficient sense of interconnection at the global level to propel the move toward a more unified international protection system of the kind proposed. There was, however, near-unanimous support for greater solidarity in refugee protection at the (more interconnected) regional level. These efforts could be orchestrated and supported at the global level.

These reservations notwithstanding, it was equally clear that the majority of contributors acknowledged the force of the Project's essential goals. Most agreed that non-entrée practices are presently undermining the implicit premise of the Refugee Convention that states are prepared to grant access to asylum. It was also agreed that the "accident of geography" approach to the allocation of burdens and responsibilities is untenable, and that the quality of protection afforded refugees is often neither fully respectful of basic norms of human dignity nor consonant with the theoretical commitment to promote the repatriation and reinte- gration of refugees in their home countries when circumstances allow. The challenge, then, was how best to draw on the Reformulation Project's insights and concrete ideas for change without running afoul of the four obstacles to a program of holistic reform noted above.

In the final analysis, we have elected to construct our follow-through at two levels. First, we will do whatever is possible to reform the refugee protection system from within. Taking account both of the reservations expressed to the present logic of comprehensive reform and of the components of the Project's work that attracted serious interest among contributors, we will promote consideration of supplementary protection mechanisms that require neither the amendment of the Refugee Convention nor the institutional restructuring of the UNHCR or national protection systems.

Second and simultaneously, we will lay the empirical and political groundwork for a more holistic reformulation of the protection regime. To avoid finding ourselves in a defensive, rearguard situation, I remain convinced that those of us concerned with the wellbeing of refugees need desperately to engage in critical thinking and to formulate concrete ideas to guide fundamental reform when and if the supplementary protection mechanisms fail adequately to reconcile the needs of refugees and states. It is important, in other words, to both act within the present context and to prepare for future eventualities.

In thinking of ways to equip the present refugee protection regime to attenuate the challenge of non-entrée, to promote enhanced solidarity among states in the provision of asylum, and to respond pragmatically to the diluted and debilitating nature of many present protection arrangements, we 
have identified two general themes we believe are worth developing for early consideration by persons and organizations concerned with refugee protection, international human rights, and global governance.

\section{Common But Differentiated Responsibility Toward Refugees}

Much of the present refugee regime's disfunction can be traced to the atomistic notion of responsibility toward refugees that has evolved since the beginning of the Cold War. States engage in non-entrée and containment practices in large measure to avoid the particularized responsibility that ensues when a refugee arrives in their territory, and frequently offer only in-

Taking into account the importance of a solid empirical foundation to the success of any proposal for even supplementary change, we propose to test the theoretical logic of responsibility and burden sharing as it is conceived, against a small number of contemporary case studies. Tentatively, the empirical component will center on (a) refugees from Bosnia seeking entry into Europe (North-to-North); (b) refugees from Rwanda and Burundi seeking entry into Zaire and Tanzania (South-to-South); and (c) refugees from Haiti seeking entry into the United States (South-to-North). The goal will be both to learn from the successes and failures of efforts to share burdens and responsibilities in each of

\section{Much of the present refugee regime's disfunction can be traced to the atomistic notion of responsibility toward refugees that has evolved since the beginning of the Cold War.}

humane "protection" as a deterrent to other would-be arrivals. Yet there is nothing in the Refugee Convention that requires states to act independently of each other in meeting the needs of refugees. To the contrary, the Preamble to the Refugee Convention points toward a degree of collaboration among states that has yet to be realized in practice.

We are now undertaking a followthrough study that investigates the value of the "risk-region" concept to define primary responsibility to receive refugees, coupled with a broadened understanding of "collective security" that would sustain interregional fiscal burden sharing and the provision of exceptional and residual asylum and resettlement. We will seek to advance thinking on the ways in which regional and global governance structures can be effectively coordinated to facilitate an "insurance model" of refugee protection, in which the incentive to take harsh and preemptive measures against refugees is attenuated as a function of diminished risk to any particular state of destination. these situations, and to analyze the viability of intra-regional responsibility sharing and inter-regional burden sharing in the actual circumstances of each of these important refugee flows.

\section{A Dignified and Solution-Oriented Approach to Refugee Protection}

While it was the consensus of the contributors to the meeting that it was neither necessary nor strategically desirable to encourage states to view temporary protection as the normal response to refugeehood, it was generally understood that in fact international law requires no more than dignified protection of refugees pending their safe return to the state of origin. It was also acknowledged that temporary protection has always been standard policy in most parts of the less developed world, and is increasingly resorted to by developed countries as well.

The concern was expressed that the granting of "temporary" protection is not infrequently treated by states as a pretext to deal with refugees without due respect for their refugee-specific and general human rights. There was consensus that it would be worthwhile to design a model of refugee rights that is specifically tailored to the psychosocial needs of persons in receipt of temporary protection, and which reinforces and contextualizes the obligations assumed by states under the Refugee Convention and general international human rights law.

Beyond designing temporary protection as a dignified and rightsregarding process, it was felt that it was equally important to promote a solution-oriented vision of temporary protection. While repatriation is, at least in principle, acknowledged to be the preferred solution to refugeehood, the mechanisms of temporary protection too often tend to work against this goal. In particular, refugees may be debilitated during temporary protection by social and physical isolation, and by the denial of access to meaningful socioeconomic activity. The "Study in Action of Repatriation and Development Assistance," in contrast, conceives of refugees as agents of a process of development to begin during temporary protection and extending well into the stage of return and reintegration. The process of development advocated in the Study is intended to engage local resources and energies in refugee, host, and stayee communities. It involves a limited international role in allocating resources, enlivening and promoting development at the local level, and ensuring accountability. The mechanisms proposed require "judicious, not lavish" external resources, and establish a continuum between emergency relief operations and longterm development assistance.

The supplementary study of "A Dignified and Solution-Oriented Approach to Refugee Protection" will therefore take present legal and institutional structures as its framework, but seek to provide guidance on how best to dovetail this framework to the reality of enhanced resort by states to temporary protection. It will serve as a principled yet practical supplement to the present understanding of the minimum acceptable standards for humane protection, and move the 
protection regime toward greater harmony with the internationally preferred solution of repatriation in safety and dignity.

\section{Consultative Research Strategy}

A major objective of the Reformulation Project has always been to reach out to the broader human rights and global governance communities, and to encourage them to join with the present circle of contributors to the Project in promoting the cause of a reinvigorated system of refugee. protection. Rather than offering a relatively finalized blueprint for change in the hope of receiving advice on implementation strategy, we intend to draw a broadly defined group of interested parties into the process of testing our hypotheses for supplemental change to the refugee protection system against their understanding of both what is needed and what is viable.

To this end, we have established a site on the World Wide Web, and we will operate an electronic mail discussion list, as well as an electronic archive of our background materials and participant responses. We see the Internet as an effective means of involving persons who have contributed to the project to-date, as well as the broader refugee protection, human rights, and global governance communities. Not only is this consultation process, as conceived, open to many more people than would be possible by strict reliance on face-to-face meetings, but the interactive written communication format should allow for a more sustained process of thoughtful reflection.

The email discussion will run from late March through the end of June, 1996. We then intend to revise the two draft papers, taking into account ideas and suggestions which arise during the discussion. The revised papers will be presented for final discussions at two regional fora, perhaps in the Autumn of 1996, before making them widely available to governments, NGOs and the academic community.

End of Focus Section

\section{Toward the Reformulation of International Refugee Law}

\section{Would You Like to Contribute?}

\section{Email Forum}

As part of its ongoing research project, "Toward the Reformulation of International Refugee Law," the Centre for Refugee Studies at Toronto's York University, under the direction of Professor James Hathaway, is organizing an email discussior of two papers, entitled "Common but Differentiated Responsibility Toward Refugees" and "A Dignified and Solution-Oriented Approach to Refugee Protection."

The discussion will run from late March through the end of June, 1996. Interested individuals can consult our home page on the Internet in late March to obtain copies of the papers. The URL will be http://www.yorku.ca/research/crs/law/RP_HP.htm.

You can also reach us now by email, at REFORM@YORKU.CA, or contact Alex Neve, Legal Programmes Coordinator, by phone or fax. If you would like to participate but do not have access to the Internet, please let us know.

\section{Would you like to obtain copies of the papers and conference proceedings?}

We expect that a volume containing the full text of the Five Studies in Action and other documents from the May 1995 SymposiumToward the Reformulation of International Refugee Law-will be published in mid-1996.

If you would like to be kept informed as to when and where that publication will be available, please contact:
Alex Neve
Legal Programmes Coordinator
Centre for Refugee Studies
York Lanes, 3rd Floor
York University
4700 Keele Street
North York ON M3J 1P3

Telephone: (416) 736-5423

Fax: (416) 736-5837

Internet: aneve@yorku.ca 